\title{
Oxygen Saturation Targeting During Delivery Room Stabilization: What Does This Mean for Regional Cerebral Oxygenation?
}

\author{
Corinna Binder-Heschl1,2, Gerhard Pichler ${ }^{1,2}$, Alexander Avian ${ }^{3}$, Bernhard Schwaberger ${ }^{1,2}$, \\ Nariae Baik-Schneditz ${ }^{1,2}$, Lukas Mileder ${ }^{1,2}$, Stefan Heschl ${ }^{4}$ and Berndt Urlesberger ${ }^{1,2 *}$ \\ ${ }^{1}$ Department of Pediatrics, Division of Neonatology, Medical University of Graz, Graz, Austria, ${ }^{2}$ Research Unit for Neonatal \\ Micro- and Macrocirculation, Department of Pediatrics, Medical University of Graz, Graz, Austria, ${ }^{3}$ Institute for Medical \\ Informatics, Statistics and Documentation, Medical University of Graz, Graz, Austria, ${ }^{4}$ Department of Anesthesiology and \\ Intensive Care Medicine, Pediatric Anesthesia, Medical University of Graz, Graz, Austria
}

\section{OPEN ACCESS}

Edited by:

Charles Christoph Roehr, University of Oxford, United Kingdom

Reviewed by:

Ju Lee Oei,

University of New South

Wales, Australia

C. Omar Farouk Kamlin,

Royal Women's Hospital, Australia Helmut Dietmar Hummler,

University of UIm, Germany

${ }^{*}$ Correspondence:

Berndt Urlesberger berndt.urlesberger@medunigraz.at

Specialty section: This article was submitted to Neonatology,

a section of the journal

Frontiers in Pediatrics

Received: 15 January 2019 Accepted: 17 June 2019

Published: 02 July 2019

Citation:

Binder-Heschl C, Pichler G, Avian A, Schwaberger B, Baik-Schneditz N, Mileder L, Heschl $S$ and Urlesberger B (2019) Oxygen Saturation Targeting During Delivery Room Stabilization: What Does This Mean for Regional Cerebral Oxygenation? Front. Pediatr. 7:274 doi: 10.3389/fped.2019.00274
Objective: To investigate if preterm neonates with arterial oxygen saturation $\left(\mathrm{SpO}_{2}\right)<80 \%$ at 5 min after birth show different regional cerebral tissue oxygen saturation $\left(\mathrm{rCStO}_{2}\right)$, compared to infants reaching the target.

Methods: Retrospective analysis of four prospective observational studies. Preterm neonates needing respiratory support during delivery room stabilization were included. Regional cerebral tissue oxygen saturation was measured with near-infrared spectroscopy (NIRS) during the first 15 min after birth along with $\mathrm{SpO}_{2}$ and heart rate $(\mathrm{HR})$. Neonates were divided into two groups: those with a 5-min $\mathrm{SpO}_{2} \geq 80 \%$ (" $\geq 80 \%$ group") and those with a 5 -min $\mathrm{SpO}_{2}<80 \%$ (“<80\% group"). Groups were compared regarding $\mathrm{rcStO}_{2}, \mathrm{SpO}_{2}$, and $\mathrm{HR}$. Furthermore, we analyzed whether a 5 -min $\mathrm{SpO}_{2}<80 \%$ was associated with a $\mathrm{rcStO}_{2}$ below the 10th percentile at the same time point.

Results: 146 neonates were included, with 68 (47\%) in the " $\geq 80 \%$ group" and 78 (53\%) in the "<80\% group." Neonates in the " $<80 \%$ group" had a significantly lower $\mathrm{rcStO}_{2}$ ( $p<0.001)$. Furthermore, $80.3 \%$ of neonates in the " $<80 \%$ group" and $23.4 \%$ in the " $\geq 80 \%$ group" had $\mathrm{rcStO}_{2}$ values below the 10th percentile at $5 \mathrm{~min}(p<0.001)$. HR was significantly lower at minute 3 and 4 in the "<80\% group" $(p<0.002)$.

Conclusion: Preterm infants needing respiratory support, who do not reach the $\mathrm{SpO}_{2}$ target of $80 \%$ at 5 min after birth, show significantly diminished $\mathrm{rcStO}_{2}$ values compared to neonates reaching the target.

Keywords: near infrared spectroscopy, regional cerebral oxygenation, respiratory support, transition period, preterm neonates, arterial oxygen saturation, target saturation

\section{INTRODUCTION}

Within the last years a significant amount of research has been undertaken trying to understand the physiological processes during neonatal transition. The course of arterial oxygen saturation $\left(\mathrm{SpO}_{2}\right)$ during the first minutes after birth became a topic of high interest in neonatal medicine, as this seems to be crucial for the infant's further outcome. Pulse oximetry monitoring in the delivery 
room is now recommended in order to gain more information about the neonate's condition and to guide respiratory and supplemental oxygen support $(1,2)$. Percentiles of postnatal rise in $\mathrm{SpO}_{2}$ were obtained from studies including healthy term and preterm infants without medical intervention (3).

In infants with need for respiratory support, adequate $\mathrm{SpO}_{2}$ targeting is very much under debate. The European Resuscitation Council and the American Heart Association published recommendations for threshold values for certain time points within the postnatal stabilization period $(1,2,4$, 5). Besides $\mathrm{SpO}_{2}$ targets, the ideal strategy of initial oxygen supplementation for delivery room resuscitation is not clear yet, and recommendations have changed substantially within the last decade (6). There seems to be a narrow range for $\mathrm{SpO}_{2}$ targeting, as preterm infants are at risk of organ injury due to biochemical oxidative stress on the one hand, but also at risk for hypoxic injury due to respiratory insufficiency on the other hand (7-11). Recently, a study by Oei et al. showed that preterm infants initially resuscitated with room air (21\% oxygen) had an increased risk of hospital death compared to infants resuscitated with $100 \%$ oxygen. Additionally, they showed that in preterm neonates, not reaching a $5-\mathrm{min}^{\mathrm{SpO}_{2}}$ of $80 \%$, risk of mortality increased $(12,13)$. The same authors performed a meta-analysis of eight randomized controlled oxygen titration trials and demonstrated that almost half of the preterm infants did not reach a 5-min $\mathrm{SpO}_{2}$ of $80 \%$. Moreover this was associated with a higher risk of developing bradycardia and intraventricular hemorrhage (IVH) (13). The brain of preterm infants is particularly vulnerable to hypoxia. However, monitoring $\mathrm{SpO}_{2}$ and heart rate (HR) by pulse oximetry may not provide adequate information about the oxygen supply to the brain, as oxygen delivery depends on $\mathrm{SpO}_{2}$ and organ perfusion (14).

A common method to measure regional cerebral oxygenation is near-infrared spectroscopy (NIRS). This non-invasive method can be used in preterm infants during delivery room stabilization (14). Moreover, reference ranges and centile charts of regional cerebral oxygenation during the first $15 \mathrm{~min}$ after birth are available for term and preterm infants without medical support $(15,16)$. A few years ago, a study showed that preterm neonates developing IVH within the first days after birth had a significantly lower regional cerebral oxygenation during immediate transition $(14,17)$. This association was also highlighted by Katheria et al. recently (18). Moreover, a randomized Phase I/II pilot trial demonstrated that monitoring regional cerebral oxygenation during neonatal resuscitation in combination with dedicated interventions reduced the burden of cerebral hypoxia and thus may be useful in guiding respiratory and supplemental oxygen support after birth (19).

Hence, the aim of the present study was to investigate whether reaching a $\mathrm{SpO}_{2}$ target of $80 \%$ at $5 \mathrm{~min}$ after birth

\footnotetext{
Abbreviations: $\mathrm{SpO}_{2}$, Arterial oxygen saturation; cTOI, Cerebral tissue oxygenation index; $\mathrm{CrSO}_{2}$, Cerebral regional oxygen saturation; HR, Heart rate; $\mathrm{rCStO}_{2}$, Regional cerebral tissue oxygen saturation; cFTOE, Cerebral fractional tissue oxygen extraction; NIRS, Near-infrared spectroscopy; IVH, Intraventricular hemorrhage; FiO2, Fraction of inspired oxygen.
}

was associated with a significantly different course of regional cerebral oxygenation.

\section{METHODS}

This study represents a retrospective analysis of four prospective observational studies, conducted between December 2010 and March 2017 at the Division of Neonatology, Department of Pediatrics and Adolescent Medicine, Medical University of Graz, Austria (19-22).

We included preterm infants, $<37$ weeks of gestation, who fulfilled all of the following criteria: (1) decision to conduct full life support, (2) obtained written, informed consent from the parents prior to birth, (3) need for respiratory support during immediate transition in the delivery room, and (4) no congenital malformations, which could affect the oxygenation or mortality. Only neonates after cesarean section were included to avoid a delay or disturbance of immediate mother-baby skin-to-skin contact in vaginally born neonates. According to the local clinical routine cord clamping was performed up to $30 \mathrm{~s}$ after birth, and neonates were stabilized according to the current resuscitation guidelines $(2,5,6,23,24)$.

The Regional Committee on Biomedical Research Ethics approved all of the included studies.

In all infants maternal medical history and neonatal demographic data, as gestational age, birth weight, Apgar scores and $\mathrm{pH}$ of the umbilical artery, were documented.

The included studies were designed to measure regional cerebral oxygenation during the first $15 \mathrm{~min}$ after birth, using NIRS. A standardized protocol was followed in all studies: the study period started when the cord was clamped and lasted for $15 \mathrm{~min}$. After the cord was clamped, the midwife took the neonate to the resuscitation table $\left(\operatorname{CosyCot}^{\mathrm{TM}}\right.$; Fisher\& Paykel Healthcare; New Zealand), placing the infant in supine position under a pre-warmed overhead heater. If the neonate was $<28$ weeks of gestation, its body was placed into a polyethylene bag. During clinical observation/ stabilization by a neonatologist a member of the research group attached a NIRS sensor to the infant's left forehead, using a gauze bandage without disturbing routine medical care. Furthermore, a pulse oximetry sensor (IntelliVue MP50 monitor; Philips; Netherland) was applied preductal, on the right palm or wrist, to monitor $\mathrm{SpO}_{2}$ and HR. All variables were automatically recorded and stored continuously in a multichannel system "alpha-trace digital MM" (BEST Medical Systems; Austria) for subsequent analysis. $\mathrm{SpO}_{2}$ and $\mathrm{HR}$ values were stored every second.

If obstruction of the upper airway was obvious, immediate suction of the oropharynx was performed. Respiratory support, as continuous positive airway pressure (CPAP) and/or positive pressure ventilation (PPV), was provided via an appropriate round silicone face mask (LSR Silicon mask no. 0/0 or 0/1; Laerdal; Norway) and the "Neopuff Infant T- Piece Resuscitator" (Perivent; Fisher\& Paykel Healthcare; New Zealand). The default settings were a gas flow of 6-8 $\mathrm{L} / \mathrm{min}$, positive end expiratory pressure of $5 \mathrm{cmH}_{2} \mathrm{O}$, peak inspiratory pressure of $25-30 \mathrm{cmH}_{2} \mathrm{O}$ and a fraction of inspired oxygen $\left(\mathrm{FiO}_{2}\right)$ of 0.3 . To measure $\mathrm{FiO}_{2}$ 
the Florian Neonatal Respiratory Function Monitor (Acutronic Medical Systems AG; Switzerland) was used.

Depending on the study, either the INVOS 5100C (INVOS cerebral/ somatic oximeter monitor; Medtronic; Minneapolis, USA) with a neonatal sensor or the NIRO 200-NX tissue oxygenation monitor (Hamamatsu Photonics; Hamamatsu City, Japan) was used to measure the cerebral regional oxygen saturation $\left(\mathrm{CrSO}_{2}\right)$ or cerebral tissue oxygenation index (cTOI), respectively. The sample rate of $\mathrm{crSO}_{2}$ was $0.13 \mathrm{~Hz}$ and of cTOI $2 \mathrm{~Hz}$. Within this manuscript $\mathrm{crSO}_{2}$ and cTOI measurements have been combined for statistical analysis and are named regional cerebral tissue oxygen saturation $\left(\mathrm{rcStO}_{2}\right)$.

Cerebral fractional tissue oxygen extraction (cFTOE) was calculated for each minute $\left[\left(\mathrm{SpO}_{2}-\mathrm{rcStO}_{2}\right) / \mathrm{SpO}_{2}\right]$.

According to the $\mathrm{SpO}_{2}$, infants were divided into two groups: those with a 5 -min $\mathrm{SpO}_{2} \geq 80 \%$ (" $\geq 80 \%$ group") and those with a 5 -min $\mathrm{SpO}_{2}<80 \%$ (" $<80 \%$ group"). Both groups were compared to each other regarding demographic data, $\mathrm{rcStO}_{2}$, $\mathrm{SpO}_{2}, \mathrm{cFTOE}, \mathrm{FiO}_{2}$, and $\mathrm{HR}$.

Furthermore, we analyzed whether not reaching an $\mathrm{SpO}_{2}$ of $80 \%$ at $5 \mathrm{~min}$ after birth was associated with a $\mathrm{rCStO}_{2}$ below the 10 th percentile at the same time point $(15,16)$.

\section{Statistical Analysis}

Baseline characteristics are presented as mean \pm standard deviation for normally distributed variables or median (range) when the distribution was skewed. The presented values of $\mathrm{rcStO}_{2}, \mathrm{SpO}_{2}, \mathrm{HR}, \mathrm{cFTOE}$, and $\mathrm{FiO}_{2}$ are means for a whole minute. Categorical variables are given with numbers and percentage. To compare demographic data between groups, a Mann-Whitney-U-test was used for non-parametric data, a Student's $t$-test for parametric data or a $X^{2}$-test for categorical measurements. In the main analysis we investigated the changes in $\mathrm{rcStO}_{2}, \mathrm{SpO}_{2}, \mathrm{HR}$, and cFTOE within the first $15 \mathrm{~min}$ after birth using a linear mixed model with a fixed effect for time and group (" $<80 \%$ group" vs. " $\geq 80 \%$ group") and a first-order autoregressive covariance structure. Since $\mathrm{rcStO}_{2}$ and $\mathrm{cFTOE}$ were measured using two different devices, a further fixed effect (device: INVOS 5100C vs. NIRO 200-NX) was included for this analysis. If for an infants measurements both devices were available, INVOS 5100C values were used for statistical analysis. Results according to these linear mixed models are presented using means and $95 \%$ confidence intervals ( $95 \% \mathrm{CI}$ ). A $p$-value $<0.05$ was considered statistically significant. The statistical analysis were performed using IBM SPSS Statistics 24 (IBM Corporation; Armonk; New York; USA).

\section{RESULTS}

Between December 2010 and March 2017, 146 preterm neonates fulfilled the entry criteria (Figure 1). In 68 infants (47\%) the $\mathrm{SpO}_{2}$ was $\geq 80 \% 5 \mathrm{~min}$ after birth, whereas 78 infants (53\%) had $\mathrm{SpO}_{2}$ values $<80 \%$ at the same time point. Demographic data of the groups are shown in Table 1. The most immature infant in the " $\geq 80 \%$ group" was $23+3$ and in the " $<80 \%$ group" $23+6$ weeks of gestational age. Our analysis includes 52 infants below a gestational age of 32 weeks.
None of the neonates died during the study period. In the " $\geq 80 \%$ group" $6(4.1 \%)$ and in the " $<80 \%$ group" 7 (5.5\%) infants had to be intubated during the study period (no significant difference, $p=0.97)$. Three infants died before hospital discharge, $1(0.7 \%)$ in the " $\geq 80 \%$ group" and $2(1.6 \%)$ in the " $<80 \%$ group" (no significant difference, $p=0.64$ ). The infant in the " $\geq 80 \%$ group" died after 5 months in the neonatal intensive care unit due to severe bronchopulmonary dysplasia. The two neonates in the " $<80 \%$ group" died because of redirection of care. In one case it was due to the parents' specific request and in the other case due to bilateral severe intraventricular hemorrhage. No other infant had severe intraventricular hemorrhage.

\section{Arterial Oxygen Saturation $\left(\mathrm{SpO}_{2}\right)$ and Heart Rate (HR)}

Over the study period, $\mathrm{SpO}_{2}$ was significantly lower in the " $<80 \%$ group" compared to the " $\geq 80 \%$ group" ( $p<0.001)$ and showed

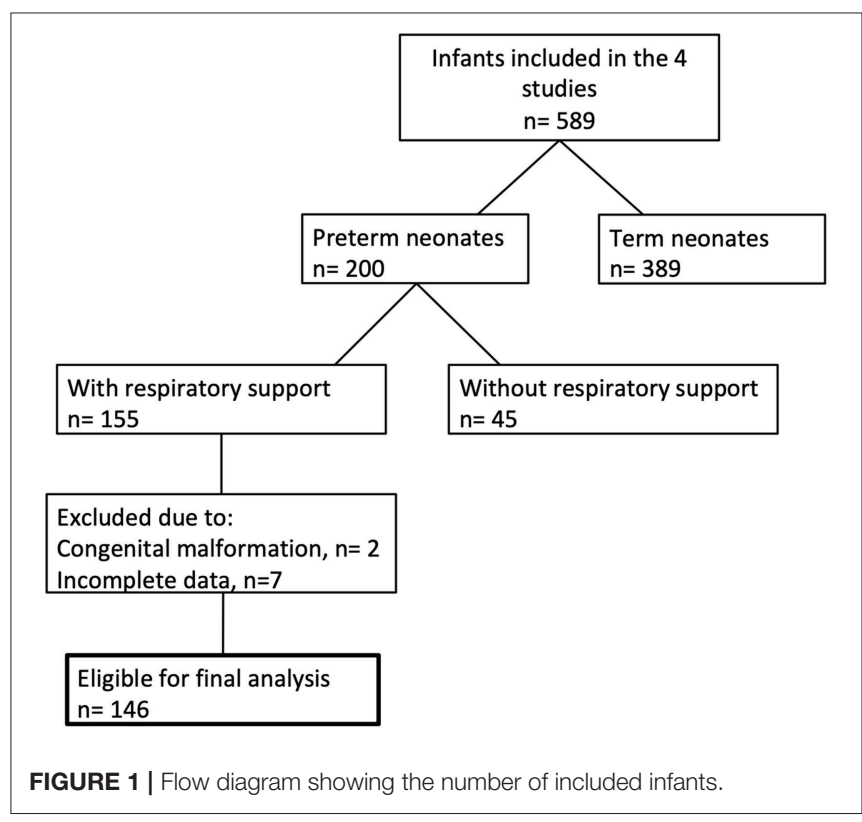

TABLE 1 | Patient demographic characteristics.

\begin{tabular}{|c|c|c|c|}
\hline & $\begin{array}{c}\geq 80 \% \text { group" } \\
n=68\end{array}$ & $\begin{array}{c}\text { "<80\% group" } \\
n=78\end{array}$ & $\begin{array}{c}\text { Group comparison } \\
p \text {-value }\end{array}$ \\
\hline $\begin{array}{l}\text { Gestational age, } \\
\text { weeks }\end{array}$ & $32.0(23.4-36.2)$ & $33.0(23.8-36.6)$ & 0.009 \\
\hline Birth weight, g & $1,484(466-3,130)$ & $1,880(550-3,105)$ & 0.001 \\
\hline Apgar 1 & $8(3-9)$ & $8(3-9)$ & 0.363 \\
\hline Apgar 5 & $9(6-10)$ & $8(6-10)$ & 0.001 \\
\hline Apgar 10 & $9(8-10)$ & $9(7-10)$ & 0.315 \\
\hline $\begin{array}{l}\text { pH umbilical } \\
\text { artery\# }\end{array}$ & $7.31 \pm 0.05$ & $7.31 \pm 0.04$ & 0.601 \\
\hline Male sex* & $34(50)$ & $32(41)$ & 0.277 \\
\hline
\end{tabular}

Data are presented as median (range), unless indicated "mean $\pm S D$, *n (\%). Bold numbers are statistically significant $(p<0.05)$. 
significantly different courses over time $(p<0.001)$. After posthoc analysis for group differences at each minute, the " $<80 \%$ group" had significantly lower $\mathrm{SpO}_{2}$ values from minute 2 to 12 (Figure 2A). At 5 minutes after birth, the mean $\mathrm{SpO}_{2}$ in the "<80\% group" was $62 \%$ (95\%CI: $60-64 \%$ ) versus $88 \%$ (95\%CI: $86-91 \%)$ in the " $\geq 80 \%$ group."

Neonates showed significantly different courses over time in their HR $(p=0.041)$. Post-hoc analysis for group differences at each minute showed that the " $<80 \%$ group" had significantly lower HR values from minute 3 to 4 (Figure 2B). In total, 8 infants (5.8\%) had $\mathrm{HR}$ values below $100 \mathrm{bpm}$ at $5 \mathrm{~min}$ of age, $6(8.2 \%)$ in the " $<80 \%$ group" and $2(3.0 \%)$ in the " $\geq 80 \%$ group," but group differences didn't reach statistical significance $(p=0.280)$.

\section{Regional Cerebral Tissue Oxygen Saturation $\left(\mathrm{rcStO}_{2}\right)$}

Over the whole study period, $\mathrm{rcStO}_{2}$ was significantly lower in the " $<80 \%$ group" compared to the " $\geq 80 \%$ group" $(p<0.001)$ and showed significantly different courses in both groups over time $(p<0.001)$. Post-hoc analysis for group differences at each minute showed that the " $<80 \%$ group" had significantly lower $\mathrm{rcStO}_{2}$ values from minute 3 to 11 (Figure 3).

Further analysis showed that 49 neonates (76.6\%) in the " $\geq 80 \%$ group," but only 14 neonates $(19.7 \%)$ in the " $<80 \%$ group" had $\mathrm{rcStO}_{2}$ values above the 10 th percentile at $5 \mathrm{~min}$ after birth $(p<0.001)(15,16)$. A subgroup analysis for each device (INVOS 5100C and NIRO 200-NX) did show same results, therefore data are not presented separately.

\section{Cerebral Fractional Tissue Oxygen Extraction (cFTOE)}

Over the study period, cFTOE showed a tendency to be lower in the " $\geq 80 \%$ group" $(p=0.065)$. Neonates in both groups showed significant different courses over time $(p=0.007)$. A post-hoc analysis for group differences at each minute revealed that infants in the " $\geq 80 \%$ group" had significantly lower cFTOE values from minute 5 to 9 (Figure 4).

\section{Fraction of Inspired Oxygen $\left(\mathrm{FiO}_{2}\right)$}

Over the study period, $\mathrm{FiO}_{2}$ was significantly higher in the " $<80 \%$ group" compared to the " $\geq 80 \%$ group" $(p<0.001)$ and showed significantly different courses over time $(p<0.001)$. According to post-hoc analysis for group differences at each minute, the " $<80 \%$ group" had significantly lower $\mathrm{FiO}_{2}$ values from minute 2 to 3 and higher values from minute 5 to 12 (Figure 5).

\section{DISCUSSION}

The present study is a retrospective analysis, which, by combining detailed course of $\mathrm{SpO}_{2}$ and $\mathrm{rcStO}_{2}$, presents a comprehensive overview on oxygenation status of preterm infants needing respiratory support immediately after birth. In contrast to Oei et al. (12) (initial $\mathrm{FiO}_{2} 0.21$ vs. 1.0) we routinely started with an $\mathrm{FiO}_{2}$ of 0.3 during postnatal stabilization, nevertheless only $47 \%$ of the preterm infants reached the $\mathrm{SpO}_{2}$ target of $80 \%$ at $5 \mathrm{~min}$ of age. Moreover, we observed that preterm neonates not reaching a $\mathrm{SpO}_{2}$ of $80 \% 5 \mathrm{~min}$ after birth had significantly lower $\mathrm{rcStO}_{2}$ values over the whole study period.

In our study the behavior of $\mathrm{SpO}_{2}$ was similar to a previous meta-analysis of eight randomized controlled oxygen titration trials, which showed that almost half of the enrolled preterm infants did not reach the target $\mathrm{SpO}_{2}$ of $80 \% 5 \mathrm{~min}$ after birth. The authors already raised the question whether recommended $\mathrm{SpO}_{2}$ targets are reached with the current oxygen supplementation strategies (13). The meta-analysis focused on 5-min $\mathrm{SpO}_{2}$ values, whereas the present study observed the course of $\mathrm{SpO}_{2}$ over the first $15 \mathrm{~min}$ after birth. The differences between the two groups in our study already occurred very early, in fact from minute 2 onwards. It also took more than $10 \mathrm{~min}$ until both groups had similar values, though the mean $\mathrm{SpO}_{2}$ of the " $<80 \%$ group" did not reach $90 \%$ at any stage of the study period. Thus, using an initial $\mathrm{FiO}_{2}$ of 0.3 , the results of the present analysis are similar to those from a recent RCT (comparing room air vs. $\mathrm{FiO}_{2}$ of 1.0 for initial delivery room resuscitation) (12). Furthermore, Rabi et al. compared the outcome of extremely preterm infants before and after the Canadian resuscitation guidelines were changed (from using $\mathrm{FiO}_{2}$ of 1.0 to using lower oxygen concentration) and found a higher risk of death and severe neurological injury in the group with low supplemental oxygen (25).

In regard to $\mathrm{FiO}_{2}$, both groups started with a default setting of 0.3. Nevertheless, we would like to point out, that our $\mathrm{FiO}_{2}$ data are measured data (using a respiratory function monitor), so they may vary slightly from set $\mathrm{FiO}_{2}$. During the first 4 min the $\mathrm{FiO}_{2}$ values were close to each other, starting with minute 5 the " $<80 \%$ group" showed significantly higher $\mathrm{FiO}_{2}$ values. Statistically the " $<80 \%$ group" had a significantly lower $\mathrm{FiO}_{2}$ during minute 2 and 3, but from a clinical point of view, both groups were still very close to each other.

It is known that $\mathrm{SpO}_{2}$ and regional cerebral oxygenation behave differently within the first minutes after birth. In fact regional cerebral oxygenation reaches a plateau earlier compared to $\mathrm{SpO}_{2}$, which may indicate a preferential oxygen delivery to the brain $(26,27)$. Oxygen delivery to the brain is affected not only by $\mathrm{SpO}_{2}$, but hemoglobin concentration and cerebral blood flow, which itself depends on cardiac output and vascular resistance. Thus, a priori it was not clear whether regional cerebral oxygenation was diminished in preterm infants presenting with a $\mathrm{SpO} 2<80 \%$. Nevertheless, $\mathrm{rcStO}_{2}$ values of the present study were significantly reduced in the $<80 \%$ group, emphasizing the point that oxygenation status of these preterm infants may be critically low or even too low. This is underlined by the fact that the $<80 \%$ group had significantly diminished HR values too. In the present study it was not the gestational age (which was lower in " $\geq 80 \%$ group"), but the clinical situation that influenced the oxygenation, as the " $<80 \%$ group" infants presented with significantly lower 5-min Apgar scores.

Dawson et al. defined percentiles for the rise of $\mathrm{SpO}_{2}$ within the first $10 \mathrm{~min}$ after birth in infants without any need for respiratory support (3). Nevertheless, in infants with need for 

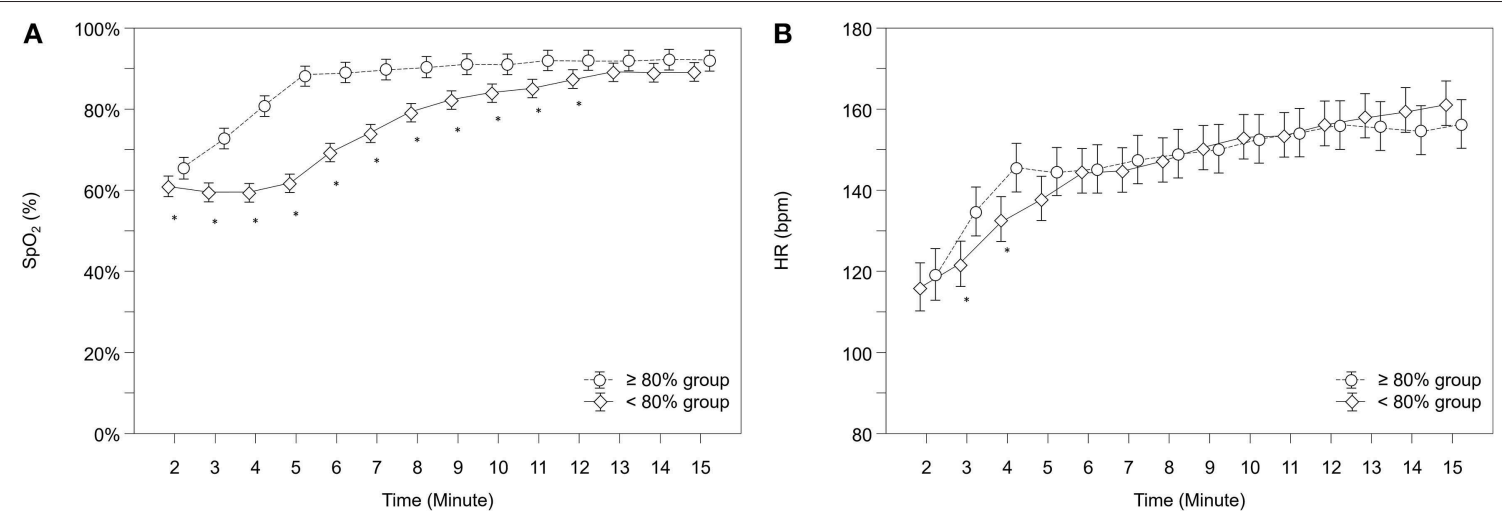

FIGURE 2 | Courses of (A) arterial oxygen saturation $\left(\mathrm{SpO}_{2}\right)$ and $\mathbf{( B )}$ heart rate $(\mathrm{HR})$ within both groups. Significant differences between groups $(p<0.05)$ for each minute are marked with *; Data are means and $95 \% \mathrm{Cl}$. Data points are slightly offset on the x-axis for visual reasons.

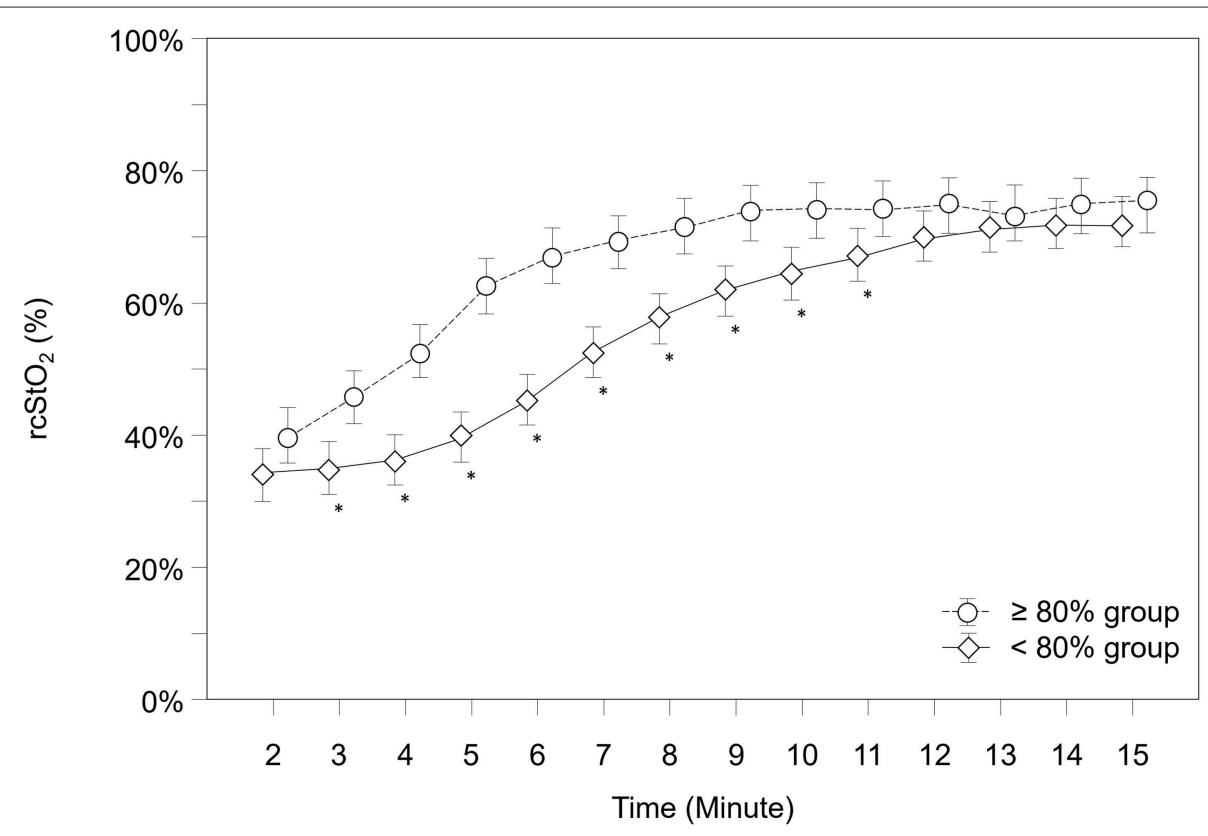

FIGURE 3 | Courses of regional cerebral tissue oxygen saturation $\left(\mathrm{rcStO}_{2}\right)$ within both groups. Significant differences between groups $(p<0.05)$ for each minute are marked with *; Data are means and $95 \% \mathrm{Cl}$. Data points are slightly offset on the x-axis for visual reasons.

respiratory support there is no evidence based data available for the selection of the best $\mathrm{SpO}_{2}$ target. In 2015 recommendations were published to target for a region equivalent the 25th percentile $(4,5)$.

To make NIRS more suitable for clinical routine, reference ranges, similar to the $\mathrm{SpO}_{2}$ percentile charts of Dawson et al. (3), have been established for term and preterm infants without medical intervention too $(15,16)$. Similar to $\mathrm{SpO}_{2}$ it still remains unclear, which regional cerebral oxygenation threshold should be targeted. In a previous study, our research group reported an associative relationship between the appearance of IVH during the first week after birth and low regional cerebral oxygenation values during immediate transition in preterm infants below 32 weeks of gestational age. Infants in the "IVH group" had significantly lower regional cerebral oxygenation values from minute 7 to 15 after birth compared to the "non-IVH group," and moreover showed $\mathrm{rcStO}_{2}$ values below the 10th percentile (17). Therefore, $\mathrm{rcStO}_{2}$ values below the 10 th percentile may be considered as worrisome. In the present study, $80.3 \%$ of infants in the " $<80 \%$ group" did show a $\mathrm{rCStO}_{2}$ below the 10 th percentile, pointing out that these neonates did not only suffer from arterial hypoxia, but also from impaired regional cerebral oxygenation, which may contribute to perinatal brain injury. Moreover, we are concerned that even $23.4 \%$ of all infants in the " $\geq 80 \%$ group" still showed $\mathrm{rCStO}_{2}$ values below the 10 th percentile. The question remains whether we can influence regional cerebral oxygenation with our clinical actions. Recently, a multicenter randomized pilot-trial (COSCOD Trial) demonstrated that an additional 


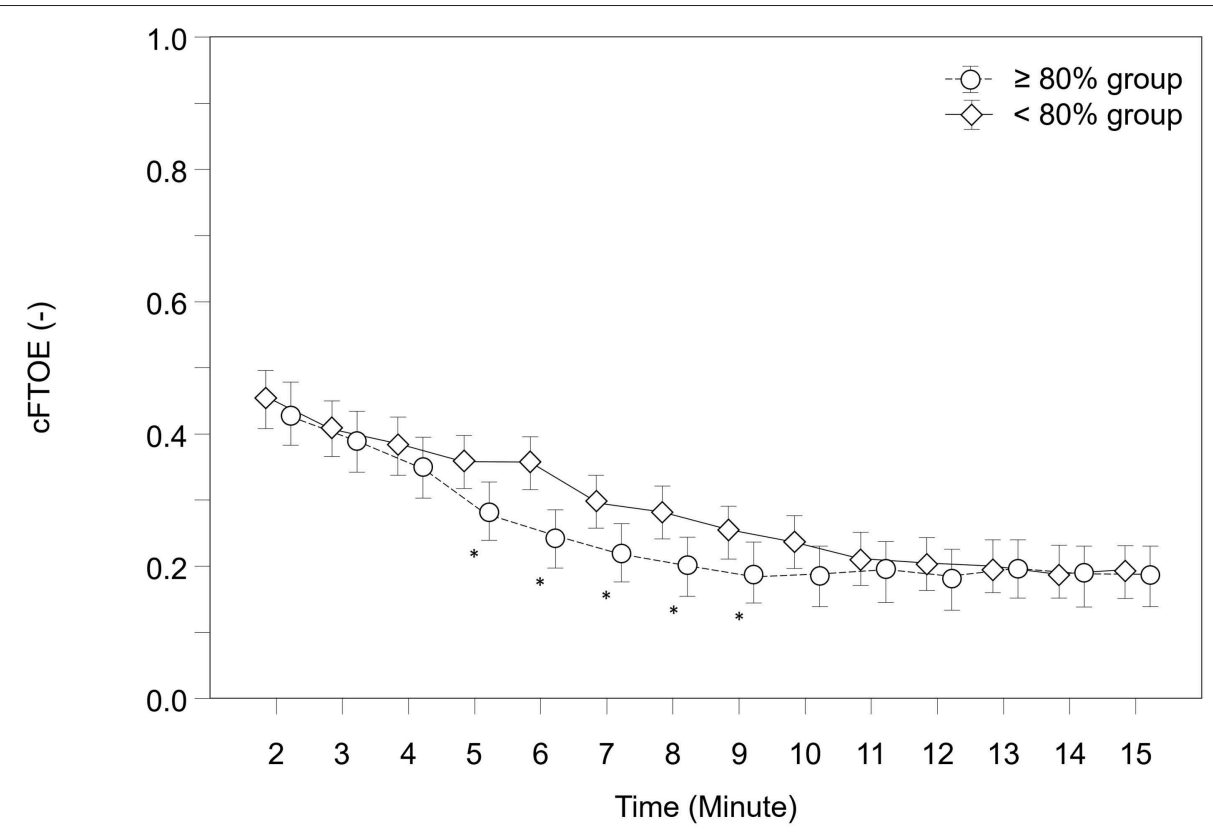

FIGURE 4 | Courses of cerebral fractional tissue oxygen extraction (CFTOE) within both groups. Significant differences between groups $(p<0.05)$ for each minute are marked with *; Data are means and $95 \% \mathrm{Cl}$. Data points are slightly offset on the $\mathrm{x}$-axis for visual reasons.

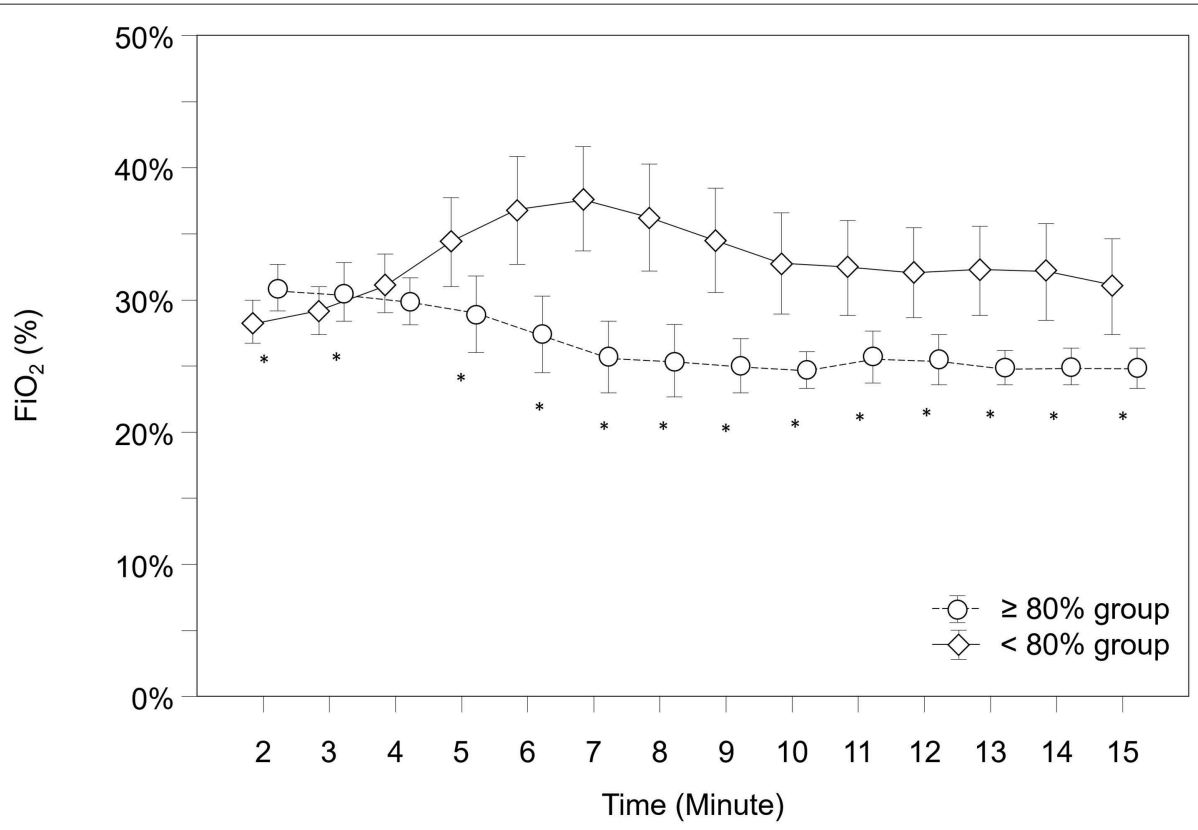

FIGURE 5 | Courses of fraction of inspired oxygen $\left(\mathrm{FiO}_{2}\right)$ within both groups. Significant differences between groups $(p<0.05)$ for each minute are marked with *; Data are means and $95 \% \mathrm{Cl}$. Data points are slightly offset on the $x$-axis for visual reasons.

monitoring of regional cerebral oxygenation in combination with clinical treatment guidelines was feasible, and that such an approach did reduce the burden of cerebral hypoxia during neonatal resuscitation (19). Furthermore, the trial proved that it was feasible to keep regional cerebral oxygenation values above the 10th percentile with the use of a dedicated clinical protocol. With the use of cerebral NIRS similar results have been described for preterm infants during the first $72 \mathrm{~h}$ by another randomized multicenter trial, the SafeboosC- trial. The study showed a reduction in the burden of cerebral hypoxia in extremely preterm infants when regional cerebral oxygenation was monitored and predefined treatment guidelines were used. 
Furthermore, the study found that low regional cerebral oxygenation during the first 3 days of life was associated with severe intracranial hemorrhage $(28,29)$. Thus, the present study does not only add further information to the topic of optimizing oxygenation during neonatal transition, but contributes to the possibility of using NIRS as a monitoring tool in that situation.

The present study has several limitations. Cerebral blood flow is regulated by cerebral vascular resistance, which is influenced by changes in $\mathrm{paO}_{2}, \mathrm{paCO}_{2}$, and blood glucose (30-32). There is evidence that cerebral blood flow correlates positively with $\mathrm{paCO}_{2}$ (33) and is increased by the presence of hypoglycemia (31). It even appears that $\mathrm{paCO}_{2}$ has more influence on cerebral blood flow than arterial blood pressure (34). In the present study no information on blood gas changes (except the arterial umbilical $\mathrm{pH}$ ) or blood glucose levels was available, therefore we cannot interpret the potential influence of these parameters. Another influencing factor on oxygen delivery is hemoglobin, which was also not measured in our study. However, we presume that clinically relevant changes in hemoglobin concentration were unlikely, since the study period was only $15 \mathrm{~min}$ short, and no serious bleedings were observed. Secondly, the cord clamping time was similar in all infants.

As described above, we only included infants delivered by cesarean section. Therefore, we have no information, whether vaginal birth would have shown different results. Though it is known, that $\mathrm{SpO}_{2}$ and $\mathrm{HR}$ are lower in cesarean-delivered infants, no differences in cerebral oxygenation could be observed with respect to mode of delivery (27).

In the present study $\mathrm{rcStO}_{2}$ was measured with two different devices, the INVOS 5100C and the NIRO 200-NX. Since these two different devices provide systematically different values we included the type of device in the analysis to avoid an influence on the results. As expected this factor resulted in significant differences between these two devices ( $\mathrm{rcStO} 2: p=0.002$; $\mathrm{cFTOE}$ : $p<0.001)$. Although these factors were included in the analysis, it cannot be ruled out that the type of device may have an influence,

\section{REFERENCES}

1. Kattwinkel J, Perlman JM, Aziz K, Colby C, Fairchild K, Gallagher J, et al. Part 15: neonatal resuscitation: 2010 American Heart Association Guidelines for Cardiopulmonary Resuscitation and Emergency Cardiovascular Care. Circulation. (2010) 122:S90919. doi: 10.1161/CIRCULATIONAHA.110.971119

2. Richmond S, Wyllie J. European Resuscitation Council Guidelines for Resuscitation 2010 Section 7. Resuscitation of babies at birth. Resuscitation. (2010) 81:1389-99. doi: 10.1016/j.resuscitation.2010.08.018

3. Dawson JA, Kamlin CO, Vento M, Wong C, Cole TJ, Donath SM, et al. Defining the reference range for oxygen saturation for infants after birth. Pediatrics. (2010) 125:e1340-7. doi: 10.1542/peds.2009-1510

4. Wyllie J, Bruinenberg J, Roehr CC, Rudiger M, Trevisanuto D, Urlesberger B. European Resuscitation Council Guidelines for Resuscitation 2015: Section 7. Resuscitation and support of transition of babies at birth. Resuscitation. (2015) 95:249-63. doi: 10.1016/j.resuscitation.2015.07.029

5. Wyckoff MH, Aziz K, Escobedo MB, Kapadia VS, Kattwinkel J, Perlman JM, et al. Part 13: Neonatal Resuscitation: 2015 American Heart Association Guidelines Update for Cardiopulmonary which we have not modeled in our analysis. It is known that absolute values of different devices are not comparable one-toone, but the differences in device calibration are well-defined and a study showed no significant differences in the mean regional tissue oxygenation between the two NIRS devices $(35,36)$. It needs to be considered that reference ranges for the NIRO 200NX device were derived from term neonates without medical intervention, who might have a higher cTOI during transition period. The reference values for the INVOS 5100C device were derived from preterm neonates too.

In conclusion, in this retrospective observational analysis we observed that preterm neonates not reaching a $\mathrm{SpO}_{2}$ of $80 \%$ 5 min after birth had a significantly lower $\mathrm{rcStO}_{2}$ over the whole study period. Furthermore, $80.3 \%$ of infants in the " $<80 \%$ group" did show $\mathrm{rcStO}_{2}$ values below the 10th percentile, and we must point out that even $23.4 \%$ of the neonates in the " $\geq 80 \%$ group" still had $\mathrm{rcStO}_{2}$ values below the 10 th percentile $5 \mathrm{~min}$ after birth. The ideal oxygen targeting and supplementation policy remains a matter of debate and needs further work. The results of the COSCOD Trial encourage the use of NIRS during neonatal resuscitation.

\section{ETHICS STATEMENT}

All data included in this retrospective study was extracted from four different prospective studies. The ethics committee of the Medical University of Graz approved all four studies. Written informed consent was obtained from all parents in accordance with the Declaration of Helsinki.

\section{AUTHOR CONTRIBUTIONS}

CB-H and BU designed the study. CB-H, GP, NB-S, BS, and $\mathrm{LM}$ collected the data. AA and $\mathrm{CB}-\mathrm{H}$ performed statistical analysis. $\mathrm{CB}-\mathrm{H}, \mathrm{SH}$, and $\mathrm{BU}$ wrote the first draft. All the authors critically reviewed the manuscript and approved the final version submitted for publication.

Resuscitation and Emergency Cardiovascular Care. Circulation. (2015) 132:S543-60. doi: 10.1161/CIR.0000000000000267

6. Perlman JM, Wyllie J, Kattwinkel J, Atkins DL, Chameides L, Goldsmith JP, et al. Part 11: Neonatal resuscitation: 2010 International Consensus on Cardiopulmonary Resuscitation and Emergency Cardiovascular Care Science With Treatment Recommendations. Circulation. (2010) 122:S51638. doi: 10.1161/CIRCULATIONAHA.110.971127

7. Vento M, Moro M, Escrig R, Arruza L, Villar G, Izquierdo I, et al. Preterm resuscitation with low oxygen causes less oxidative stress, inflammation, and chronic lung disease. Pediatrics. (2009) 124:e43949. doi: 10.1542/peds.2009-0434

8. Vento M, Aguar M, Escobar J, Arduini A, Escrig R, Brugada M, et al. Antenatal steroids and antioxidant enzyme activity in preterm infants: influence of gender and timing. Antioxid Redox Signal. (2009) 11:294555. doi: 10.1089/ars.2009.2671

9. Vento M, Sastre J, Asensi MA, Vina J. Room-air resuscitation causes less damage to heart and kidney than 100\% oxygen. Am J Respir Crit Care Med. (2005) 172:1393-8. doi: 10.1164/rccm.200412-1740OC

10. Saugstad OD. Oxygen and retinopathy of prematurity. J Perinatol. (2006) 26(Suppl. 1):S46-50, Discussion S63-4. doi: 10.1038/sj.jp.7211475 
11. Saugstad OD. Bronchopulmonary dysplasia-oxidative stress and antioxidants. Semin Neonatol. (2003) 8:39-49. doi: 10.1016/S1084-2756(02)00194-X

12. Oei JL, Saugstad OD, Lui K, Wright IM, Smyth JP, Craven P, et al. Targeted oxygen in the resuscitation of preterm infants, a randomized clinical trial. Pediatrics. (2017) 139:e20161452 doi: 10.1542/peds.2016-1452

13. Oei JL, Finer NN, Saugstad OD, Wright IM, Rabi Y, Tarnow-Mordi W, et al. Outcomes of oxygen saturation targeting during delivery room stabilisation of preterm infants. Arch Dis Child Fetal Neonatal Ed. (2017) 103:F44654. doi: 10.1136/archdischild-2016-312366

14. Fuchs H, Lindner W, Buschko A, Almazam M, Hummler HD, Schmid MB. Brain oxygenation monitoring during neonatal resuscitation of very low birth weight infants. J Perinatol. (2011) 32:356-62. doi: 10.1038/jp.2011.110

15. Pichler G, Binder C, Avian A, Beckenbach E, Schmolzer GM, Urlesberger B. Reference ranges for regional cerebral tissue oxygen saturation and fractional oxygen extraction in neonates during immediate transition after birth. $J$ Pediatric. (2013) 163:1558-63. doi: 10.1016/j.jpeds.2013.07.007

16. Baik N, Urlesberger B, Schwaberger B, Schmolzer GM, Mileder L, Avian A, et al. Reference ranges for cerebral tissue oxygen saturation index in term neonates during immediate neonatal transition after birth. Neonatology. (2015) 108:283-6. doi: 10.1159/000438450

17. Baik N, Urlesberger B, Schwaberger B, Schmolzer GM, Avian A, Pichler G. Cerebral haemorrhage in preterm neonates: does cerebral regional oxygen saturation during the immediate transition matter? Arch Dis Child Fetal Neonatal Ed. (2015) 100:F422-7. doi: 10.1136/archdischild-2014-307590

18. Katheria AC, Harbert MJ, Nagaraj SB, Arnell K, Poeltler DM, Brown MK, et al. The Neu-Prem trial: neuromonitoring of brains of infants born preterm during resuscitation-a prospective observational cohort study. J Pediatric. (2018) 198:209-13.e3. doi: 10.1016/j.jpeds.2018.02.065

19. Pichler G, Urlesberger B, Baik N, Schwaberger B, Binder-Heschl C, Avian A, et al. Cerebral oxygen saturation to guide oxygen delivery in preterm neonates for the immediate transition after birth: a 2-center randomized controlled pilot feasibility trial. J Pediatric. (2016) 170:73-8.e14. doi: 10.1016/j.jpeds.2015.11.053

20. Schwaberger B, Pichler G, Avian A, Binder-Heschl C, Baik N, Urlesberger B. Do sustained lung inflations during neonatal resuscitation affect cerebral blood volume in preterm infants? A randomized controlled pilot study. PLoS ONE. (2015) 10:e0138964. doi: 10.1371/journal.pone.0138964

21. Freidl T, Baik N, Pichler G, Schwaberger B, Zingerle B, Avian A, et al. Haemodynamic transition after birth: a new tool for non-invasive cardiac output monitoring. Neonatology. (2017) 111:55-60. doi: 10.1159/000446468

22. Binder C, Urlesberger B, Avian A, Pocivalnik M, Muller W, Pichler G. Cerebral and peripheral regional oxygen saturation during postnatal transition in preterm neonates. J Pediatric. (2013) 163:394-9. doi: 10.1016/j.jpeds.2013.01.026

23. Perlman JM, Wyllie J, Kattwinkel J, Atkins DL, Chameides L, Goldsmith JP, et al. Neonatal resuscitation: 2010 International Consensus on Cardiopulmonary Resuscitation and Emergency Cardiovascular Care Science with Treatment Recommendations. Pediatrics. (2010) 126:e1319-44. doi: 10.1542/peds.2010-2972B

24. Wyllie J, Perlman JM, Kattwinkel J, Wyckoff MH, Aziz K, Guinsburg R, et al. Part 7: Neonatal resuscitation: 2015 International Consensus on Cardiopulmonary Resuscitation and Emergency Cardiovascular Care Science with Treatment Recommendations. Resuscitation. (2015) 95:e169201. doi: 10.1542/peds.2015-3373D

25. Rabi Y, Lodha A, Soraisham A, Singhal N, Barrington K, Shah PS. Outcomes of preterm infants following the introduction of room air resuscitation. Resuscitation. (2015) 96:252-9. doi: 10.1016/j.resuscitation.201 5.08 .012

26. Urlesberger B, Grossauer K, Pocivalnik M, Avian A, Muller W, Pichler G. Regional oxygen saturation of the brain and peripheral tissue during birth transition of term infants. J Pediatric. (2010) 157:740-4. doi: 10.1016/j.jpeds.2010.05.013

27. Urlesberger B, Kratky E, Rehak T, Pocivalnik M, Avian A, Czihak J, et al. Regional oxygen saturation of the brain during birth transition of term infants: comparison between elective cesarean and vaginal deliveries. J Pediatric. (2011) 159:404-8. doi: 10.1016/j.jpeds.2011.02.030

28. Hyttel-Sorensen S, Pellicer A, Alderliesten T, Austin T, van Bel F, Benders $M$, et al. Cerebral near infrared spectroscopy oximetry in extremely preterm infants: phase II randomised clinical trial. BMJ. (2015) 350:g7635. doi: 10.1136/bmj.g7635

29. Plomgaard AM, Alderliesten T, Austin T, van Bel F, Benders M, Claris O, et al. Early biomarkers of brain injury and cerebral hypo- and hyperoxia in the SafeBoosC II trial. PLoS ONE. (2017) 12:e0173440. doi: 10.1371/journal.pone.0173440

30. Pryds O, Greisen G, Skov LL, Friis-Hansen B. Carbon dioxiderelated changes in cerebral blood volume and cerebral blood flow in mechanically ventilated preterm neonates: comparison of near infrared spectrophotometry and 133Xenon clearance. Pediatr Res. (1990) 27:445-9. doi: 10.1203/00006450-199005000-00006

31. Pryds O, Christensen NJ, Friis-Hansen B. Increased cerebral blood flow and plasma epinephrine in hypoglycemic, preterm neonates. Pediatrics. (1990) 85:172-6.

32. Wong FY, Alexiou T, Samarasinghe T, Brodecky V, Walker AM. Cerebral arterial and venous contributions to tissue oxygenation index measured using spatially resolved spectroscopy in newborn lambs. Anesthesiology. (2010) 113:1385-91. doi: 10.1097/ALN.0b013e3181fc5567

33. Sorensen LC, Greisen G. Precision of measurement of cerebral tissue oxygenation index using near-infrared spectroscopy in preterm neonates. $J$ Biomed Opt. (2006) 11:054005. doi: 10.1117/1.2357730

34. Noori S, Stavroudis TA, Seri I. Systemic and cerebral hemodynamics during the transitional period after premature birth. Clin Perinatol. (2009) 36:72336. doi: 10.1016/j.clp.2009.07.015

35. Hyttel-Sorensen S, Sorensen LC, Riera J, Greisen G. Tissue oximetry: a comparison of mean values of regional tissue saturation, reproducibility and dynamic range of four NIRS-instruments on the human forearm. Biomed Opt Express. (2011) 2:3047-57. doi: 10.1364/BOE.2.003047

36. Kleiser S, Ostojic D, Andresen B, Nasseri N, Isler H, Scholkmann $\mathrm{F}$, et al. Comparison of tissue oximeters on a liquid phantom with adjustable optical properties: an extension. Biomed Opt Express. (2017) 9:86101. doi: 10.1364/BOE.9.000086

Conflict of Interest Statement: The authors declare that the research was conducted in the absence of any commercial or financial relationships that could be construed as a potential conflict of interest.

Copyright (C) 2019 Binder-Heschl, Pichler, Avian, Schwaberger, Baik-Schneditz, Mileder, Heschl and Urlesberger. This is an open-access article distributed under the terms of the Creative Commons Attribution License (CC BY). The use, distribution or reproduction in other forums is permitted, provided the original author(s) and the copyright owner(s) are credited and that the original publication in this journal is cited, in accordance with accepted academic practice. No use, distribution or reproduction is permitted which does not comply with these terms. 